\title{
Fibrotic interstitial lung diseases and air pollution: a systematic literature review
}

\author{
Sergio Harari (10 1,2,3,9 , Ganesh Raghu ${ }^{4,9}$, Antonella Caminati ${ }^{1}$, Mario Cruciani ${ }^{5,6}$, \\ Massimo Franchini ${ }^{5,7}$ and Piermannuccio Mannucci ${ }^{8}$
}

\begin{abstract}
Affiliations: ${ }^{1}$ U.0. di Pneumologia e Terapia Semi-Intensiva Respiratoria - Servizio di Fisiopatologia Respiratoria ed Emodinamica Polmonare, Ospedale San Giuseppe - MultiMedica IRCCS, Milan, Italy. ${ }^{2}$ Dept of Medical Sciences, San Giuseppe Hospital MultiMedica IRCCS, Milan, Italy. ${ }^{3}$ Dept of Clinical Sciences and Community Health, Università degli Studi di, Milan, Italy. ${ }^{4}$ Center for Interstitial Lung Diseases, Dept of Medicine, University of Washington, Seattle, WA, USA. ${ }^{5}$ Italian National Blood Centre, National Institute of Health, Rome, Italy. ${ }^{6}$ Infection Control Committee and Antibiotic Stewardship Programme, AULSS9 Scaligera, Verona, Italy. ${ }^{7}$ Dept of Hematology and Transfusion Medicine, Carlo Poma Hospital, Mantua, Italy. ${ }^{8}$ Scientific Direction, IRCCS Ca' Granda Maggiore Policlinico Hospital Foundation, Milan. 'Both authors contributed equally.
\end{abstract}

Correspondence: Antonella Caminati, U.O. di Pneumologia e Terapia Semi-Intensiva Respiratoria - Servizio di Fisiopatologia Respiratoria ed Emodinamica Polmonare. Ospedale San Giuseppe - MultiMedica IRCCS, via San Vittore 12, 20123 Milan, Italy. E-mail: lafittaQlibero.it

@ERSpublications

There is supporting evidence to link ambient air pollution exposure and manifestation of IPF and F-ILD with poor outcomes. The WHO and governmental agencies need to take action to minimise factors contributing to air pollution. https://bit.ly/3bmGzKg

Cite this article as: Harari S, Raghu G, Caminati A, et al. Fibrotic interstitial lung diseases and air pollution: a systematic literature review. Eur Respir Rev 2020; 29: 200093 [https://doi.org/10.1183/ 16000617.0093-2020].

\section{ABSTRACT}

Background: Air pollution is hypothesised to be a risk factor for interstitial lung diseases (ILD). This study systematically reviewed the literature regarding the impact of air pollution on idiopathic pulmonary fibrosis (IPF) and fibrotic interstitial lung diseases (ILD).

Methods: A computer-assisted literature search of electronic databases was performed to identify studies focused on the association between ILDs and air pollution. Other inclusion criteria required that the article had to be: 1) original; 2) a prospective or retrospective study; and 3) fully published in English. Both randomised clinical trials and observational studies were considered.

Results: Only seven studies met the inclusion criteria. All studies investigated the relationship between pollution and IPF, except one that dealt with the relationship between pollution and hypersensitivity pneumonitis. Outcome measures included exacerbation of IPF, mortality, disease severity, prevalence of hypersensitivity pneumonitis, progression and incidence of IPF. On the whole, air pollution levels were negatively associated with outcomes in patients with IPF and fibrotic ILD outcome. The heterogeneity in the measurement and reporting of the end-points limited the performance of a quantitative synthesis of data. Conclusions: This systematic review provides supporting evidence linking exposure to air pollution to poor outcomes in patients with IPF and fibrotic ILD.

\section{Introduction}

Interstitial lung diseases (ILDs) are a heterogeneous group of diseases, with several known and unknown causes and characterised by infiltrates in both lungs. Several intrinsic and extrinsic risk factors are implicated in the pathogenesis of otherwise idiopathic interstitial pneumonias [1]. Idiopathic pulmonary

Provenance: Submitted article, peer reviewed.

Received: 27 April 2020 | Accepted: 4 May 2020

Copyright $\odot$ ERS 2020. This article is open access and distributed under the terms of the Creative Commons Attribution Non-Commercial Licence 4.0. 
fibrosis (IPF) is a chronic and progressive fibrotic lung disease with a severe prognosis and a median survival of 3-5 years from diagnosis [2]. Air pollution is a global problem and a neglected factor in the pathogenesis of ILD. The importance of eliminating occult environmental factors in evaluating patients with ILD is emphasised in the new guideline for diagnosis of IPF [3].

There is evidence that both genetic and environmental factors are involved in the development of IPF [46]. Smoking, occupational exposure to metals, wood dust and viruses such as the Epstein-Barr virus are all associated with IPF incidence [7-12], JOHANNSON et al. [13] observed an association between the risk of acute exacerbations of IPF and ozone $\left(\mathrm{O}_{3}\right)$ and nitrogen dioxide $\left(\mathrm{NO}_{2}\right)$ concentrations, suggesting that air pollution may contribute to disease worsening. More recently, exposure to particulate matter (PM) was found to be associated to increased mortality [14], progression of IPF [15] and disease severity, the latter also being associated with higher levels of $\mathrm{NO}_{2}$ [16]. A positive association between $\mathrm{NO}_{2}$ levels and incidence of IPF was also described [17].

These few studies and the large body of evidence supporting the short- and long-term effects of air pollution on respiratory diseases (including COPD, asthma, lung cancer and lung transplant recipients [18-21]) point to further investigation of the relationship between air pollution and IPF. Air pollution has been implicated as a triggering factor for telomere shortening and accelerated senescence, oxidantantioxidant dysregulation and chronic inflammation, all potential causes of premature exhaustion and abnormalities of alveolar re-epithelialisation, and thus postulated in the pathogenesis of IPF [22]. These mechanisms are linked with different pollutants $\left(\mathrm{O}_{3}, \mathrm{NO}_{2}, \mathrm{PM}\right)$. Similar correlations have been reported for other ILDs such as hypersensitivity pneumonitis [23] and interstitial lung abnormalities, that is, early interstitial changes that indicate subclinical ILD [24]. With this background and gaps of knowledge, we undertook a systematic review of the studies published to date and report the findings.

\section{Material and methods}

\section{Search strategy and search terms}

A computer-assisted literature search of the electronic databases MEDLINE (through PUBMED), EMBASE, SCOPUS, OVID and Cochrane Library was performed (latest search 10 June 2019) in order to identify studies on the association between ILD and air pollution. A combination of the following key words was used to maximise search specificity and sensitivity: "cryptogenic organizing pneumonia", "bronchiolitis obliterans organizing pneumonia", "desquamative interstitial pneumonitis", "respiratory bronchiolitis interstitial lung disease", "acute interstitial pneumonia", "lymphocytic pneumonia", "idiopathic pulmonary fibrosis", "interstitial lung disease", "fibrotic interstitial lung disease", "idiopathic interstitial pneumonia", "cryptogenic fibrosing alveolitis", "post-inflammatory pulmonary fibrosis" "hypersensitivity pneumonitis", "extrinsic allergic alveolitis”, “allergic extrinsic pneumonia”, "interstitial lung abnormalities", "non-specific interstitial pneumonia", "eosinophilic pneumonia", "pulmonary Langerhans" cell granulomatosis", "air pollution", "ambient particulate matter", "PM", "environmental”, and "atmospheric pollution". In addition, a manual search was carried out encompassing the references of the included studies and other reviews in order to identify potentially eligible studies not captured by the initial literature search based upon the electronic databases.

\section{Study selection and inclusion/exclusion criteria}

Study selection was performed independently by two reviewers (M. Franchini and M. Cruciani), with any disagreement resolved through discussion, as well as on the basis of the opinion of a third reviewer (S. Harari). Eligibility assessment was based on the title or abstract and on the full text if necessary. Articles were eligible for this systematic review if they indicated in the title or abstract the association between air pollution and ILD. Other inclusion criteria were that the article had to be: 1) original; 2) based upon prospective or retrospective studies; and 3) fully published in English in the past 20 years (1999-2019). Both randomised clinical trials and observational studies were considered. Case series, case reports and studies enrolling fewer than 20 patients were excluded.

\section{Data extraction}

For each study included in this systematic review, the following data were independently extracted by two reviewers (M. Franchini and M. Cruciani): first author, year of publication, study design, country of origin of the study, sample size, median age and range, and sex distribution. The main study results were also evaluated. Disagreement was resolved by consensus and by means of the opinion of a third reviewer (S. Harari), if necessary.

\section{Assessment of risk of bias in the included studies}

As no randomised controlled trials were found in the frame of this systematic review, we assessed the methodological quality of the observational studies following the recommendations from the Cochrane 
Handbook for Systematic Reviews of Interventions on assessing the quality of nonrandomised studies [25]. We used the Newcastle-Ottawa quality assessment scale (NOS) in order to assess the quality of cohort studies [26]. The methodological quality of cohort studies was assessed by evaluating case selection (four questions relating to the representativeness of the cohort, selection of the unexposed cohort, ascertainment of exposure and demonstration that the outcome of interest was not already present at the start of the study), comparability (exposed and unexposed individuals had to be matched in the design and/or confounders adjusted for in the analysis) and outcomes (three questions relating to the assessment of outcomes, follow-up long enough for outcomes to occur, and follow-up losses). Using the NOS, a study can be given a maximum of four stars for selection, two for comparability and three for outcome.

\section{Results}

Figure 1 shows the study selection flow chart. The initial search identified 398 studies with suitable data through key words and reference search. After screening the titles and abstracts and a subsequent full text review, only seven studies fulfilled eligibility criteria. Table 1 summarises the main characteristics and results of the seven studies included in the analysis. Five of them were prospective and two were retrospective cohort studies. Three studies were conducted in North America, two in Europe (Italy and France) and two in Asia (South Korea and India). All studies investigated the relationship between air pollution and IPF, except for one that investigated the relationship between pollution and hypersensitivity pneumonitis, and all were published within the past 6 years (one in 2014, two in 2017, three in 2018 and one in 2019). Sample size varied substantially across the studies. Specific air pollutants assessed by the studies comprised fine particles, particles with a 50\% cut-off aerodynamic diameter of $<2.5 \mu \mathrm{m}$ in diameter $\left(\mathrm{PM}_{2.5}\right)[14-16,23,24], \mathrm{PM}<10 \mu \mathrm{m}$ in diameter $\left(\mathrm{PM}_{10}\right)$ [13-17], $\mathrm{O}_{3}[13-17,24]$, and $\mathrm{NO}_{2}[13-17,24]$. Some studies investigated prevalent urban populations [14, 23, 24]. Other studies involved urban, suburban and rural areas [15-17]. In almost all studies pollutants were measured thought fixed air monitors [13-16, 23, 24]. ConTI et al. [17] used background and traffic monitoring stations for measurement of $\mathrm{NO}_{2}$ and $\mathrm{O}_{3}$ and satellite aerosol optical depth measurements for $\mathrm{PM}_{10}$. Outcome measures included exacerbation of IPF [13, 14], mortality [14], prevalence of hypersensitivity pneumonitis [23], progression of IPF expressed as forced vital capacity (FVC) decline [15] and disease severity [16], incidence of IPF [17] and presence and progression of interstitial lung abnormalities [24]. The end-points evaluated in the included studies were different and heterogeneous; hence, it was not possible to perform a

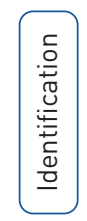

398 citations identified through primary electronic and manual search

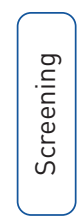

311 citations excluded as not relevant according to the title and/or abstract

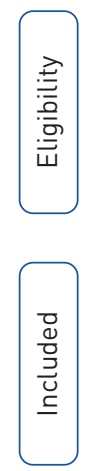

87 potentially relevant records screened by 2 reviewers (full-text articles assessed for eligibility)

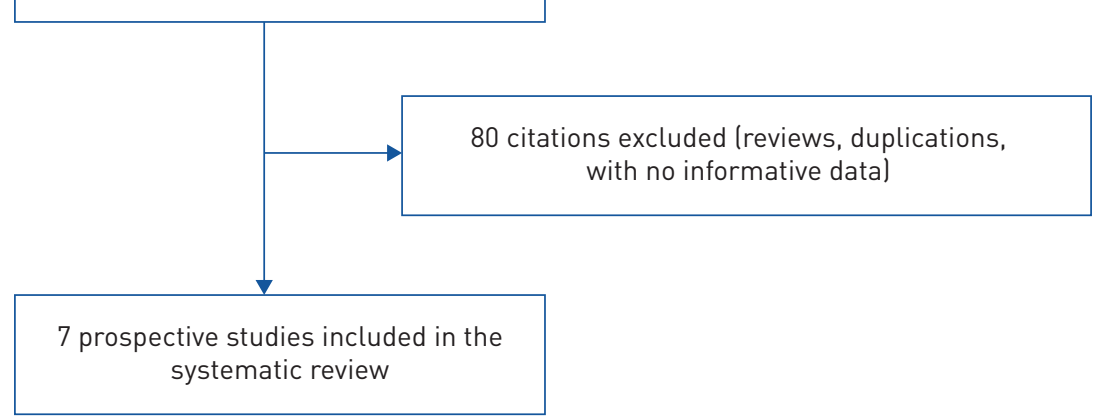

FIGURE 1 Flow chart of the study selection. 
TABLE 1 Characteristics and main results of the studies on the association between air pollution and intestinal lung disease (ILD)

\begin{tabular}{|c|c|c|c|c|c|c|c|}
\hline $\begin{array}{l}\text { First author } \\
\text { [ref.] }\end{array}$ & Study design & Study goals & Country & $\begin{array}{c}\text { Study } \\
\text { population }\end{array}$ & $\begin{array}{l}\text { Males/ } \\
\text { females }\end{array}$ & Age years & Main results \\
\hline $\begin{array}{l}\text { JoHANNSON } \\
{[13]}\end{array}$ & $\begin{array}{l}\text { Longitudinal prospective } \\
\text { cohort study }\end{array}$ & $\begin{array}{l}\text { Relationship between air } \\
\text { pollution exposure and } \\
\text { acute IPF exacerbations }\end{array}$ & $\begin{array}{l}\text { South } \\
\text { Korea }\end{array}$ & $\begin{array}{l}436 \text { patients } \\
\text { with IPF }\end{array}$ & $345 / 91$ & $62.8 \pm 7.9$ & $\begin{array}{l}\text { Statistically significant association between an } \\
\text { increased mean level of ambient } \mathrm{O}_{3} \text { in the previous } \\
6 \text { weeks and acute exacerbations of IPF (HR 1.57, } \\
95 \% \mathrm{Cl} 1.09-2.24 \text { ) and } \mathrm{NO}_{2} \text { (HR } 1.41,95 \% \mathrm{Cl} 1.04- \\
1.91 \text { ) }\end{array}$ \\
\hline SesÉ [14] & $\begin{array}{l}\text { Longitudinal prospective } \\
\text { cohort study }\end{array}$ & $\begin{array}{l}\text { Short- and long-term } \\
\text { effects of ambient air } \\
\text { pollution on the natural } \\
\text { history of IPF }\end{array}$ & France & $\begin{array}{l}192 \text { patients } \\
\text { with IPF }\end{array}$ & $148 / 44$ & $67.9 \pm 11.2$ & $\begin{array}{l}\text { Onset of adverse events was associated with an } \\
\text { increased mean level of } \mathrm{O}_{3} \text { in the } 6 \text { preceding } \\
\text { weeks, with a } \mathrm{HR} \text { of } 1.47(95 \% \mathrm{Cl} 1.13-1.92) \text { per } \\
\left.10 \mu \mathrm{g} \text { per } \mathrm{m}^{3} \text { ( } \mathrm{p}=0.005\right) \mathrm{Mortality} \text { was associated } \\
\text { with increased exposure to } \mathrm{PM}_{10}(\mathrm{HR} 2.01,95 \% \mathrm{Cl} \\
\left.1.07-3.77) \text { per } 10 \mu \mathrm{g} \text { per } \mathrm{m}^{3} \text { ( } \mathrm{p}=0.03\right) \text {, and } \mathrm{PM}_{2.5} \\
\text { (HR } 7.93,95 \% \mathrm{Cl} 2.93-21.33) \text { per } 10 \mu \mathrm{g} \text { per } \mathrm{m}^{3} \\
\text { (p<0.001) } \\
\text { A } 10 \text {-unit increase in average concentrations of } \\
\text { pollutants is considered an appropriate exposure } \\
\text { change to measure a related clinical effect }\end{array}$ \\
\hline SACK $[24]$ & Prospective cohort study & $\begin{array}{l}\text { Relationship between air } \\
\text { pollution and subclinical ILD }\end{array}$ & USA & 2671 & $1235 / 1436$ & $60.1 \pm 9.5$ & $\begin{array}{l}\text { Exposure to ambient nitrogen oxides was associated } \\
\text { with a higher prevalence of subclinical ILD (OR } \\
1.77,95 \% \mathrm{Cl} 1.06-2.95 ; \mathrm{p}=0.03 \text { ) }\end{array}$ \\
\hline $\begin{array}{l}\text { WinterbotTom } \\
\text { [15] }\end{array}$ & Retrospective cohort study & $\begin{array}{l}\text { Long-term functional } \\
\text { effects of PM exposure }\end{array}$ & USA & $\begin{array}{l}135 \text { patients } \\
\text { with IPF }\end{array}$ & $101 / 34$ & $68(46-92)$ & $\begin{array}{l}\text { Association between } \mathrm{PM}_{10} \text { levels and the rate of } \\
\text { decline in FVC during the study period; each } \mu \mathrm{g} \text { per } \\
\mathrm{m}^{3} \text { increase in } \mathrm{PM}_{10} \text { corresponding to an additional } \\
46 \mathrm{~mL} \text { in } \mathrm{FVC} \text { per year ( } \mathrm{p}=0.008)\end{array}$ \\
\hline Contı [17] & $\begin{array}{l}\text { Longitudinal retrospective } \\
\text { cohort of aggregate data } \\
\text { from a regional database }\end{array}$ & $\begin{array}{l}\text { Long-term effects of } \mathrm{PM}_{10} \\
\mathrm{NO}_{2} \text { and } \mathrm{O}_{3} \text { exposure on IPF } \\
\text { incidence }\end{array}$ & Italy & $\begin{array}{l}2090 \text { incident } \\
\text { IPF cases }\end{array}$ & & & $\begin{array}{l}\text { An increment of } 10 \mu \mathrm{g} \text { per } \mathrm{m}^{3} \text { in } \mathrm{NO}_{2} \text { concentration } \\
\text { was associated with a } 7.93 \% \text { ( } 95 \% \mathrm{Cl} 0.36-16.08 \% \text { ) } \\
\text { increase in the incidence rate of IPF } \\
\text { The traffic pollution (major in urban areas) may be } \\
\text { involved in the fibrotic process development }\end{array}$ \\
\hline $\begin{array}{l}\text { JoHANNSON } \\
{[16]}\end{array}$ & $\begin{array}{l}\text { Longitudinal prospective } \\
\text { cohort study }\end{array}$ & $\begin{array}{l}\text { Relationship between air } \\
\text { pollution exposure and lung } \\
\text { function }\end{array}$ & USA & $\begin{array}{l}25 \text { patients } \\
\text { with IPF }\end{array}$ & $21 / 4$ & $73.6 \pm 7.5$ & $\begin{array}{l}\text { Higher average exposures to } \mathrm{NO}_{2}, \mathrm{PM}_{2.5} \text { and } \mathrm{PM}_{10} \\
\text { were associated with lower } \mathrm{FVC} \text { in patients with IPF }\end{array}$ \\
\hline SINGH [23] & $\begin{array}{l}\text { Prospective data from } \\
\text { ILD-India Registry }\end{array}$ & $\begin{array}{l}\text { Relationship between } \\
\text { ambient air pollution and } \\
\text { HP }\end{array}$ & India & $\begin{array}{l}386 \text { patients } \\
\text { with HP }\end{array}$ & & & $\begin{array}{l}\text { An increment of } 10 \mu \mathrm{g} \text { per } \mathrm{m}^{3} \text { in } \mathrm{PM}_{2.5} \text { level was } \\
\text { associated with a } 7 \% \text { increase }(95 \% \mathrm{Cl} 1-13 \%) \text { in } \\
\text { the risk of developing HP }\end{array}$ \\
\hline
\end{tabular}


quantitative synthesis of the data. Nonetheless, all the studies found air pollution levels to be negatively associated with different aspects of IPF and ILD outcomes. Tables 2 and 3 show criterion-specific and global ratings from the study quality assessment.

\section{Bias assessment}

The results of the NOS are shown in tables 2 and 3. The quality of cohort studies was assessed by examining selection, comparability and outcome. Of the seven studies included, six achieved the maximum of four stars for selection, two stars for comparability and three stars for outcomes. One study achieved the maximum of two stars for comparability, three stars for selection (selected population) and two stars for outcomes (follow-up not long enough for the outcome to occur).

\section{Discussion}

To our knowledge, this is the first study that systematically reviewed the existing literature regarding the impact of ambient air pollution on IPF and ILD. Our search identified only seven studies, all published within the last 6 years, that helped to provide evidence linking air pollutants $\left(\mathrm{PM}_{2.5}, \mathrm{PM}_{10}, \mathrm{O}_{3}\right.$ and $\left.\mathrm{NO}_{2}\right)$

TABLE 2 Newcastle-Ottawa scale to evaluate the methodological quality of cohort studies included in the systematic review

\begin{tabular}{lcccccc}
\multicolumn{6}{c}{ First author [ref.] } \\
\hline SACK & SESÉ & Winterbottom & SINGH & ContI & JohanNson & JohanNSON \\
{$[24]$} & {$[14]$} & {$[15]$} & {$[23]$} & {$[17]$} & {$[13]$} & {$[16]$}
\end{tabular}

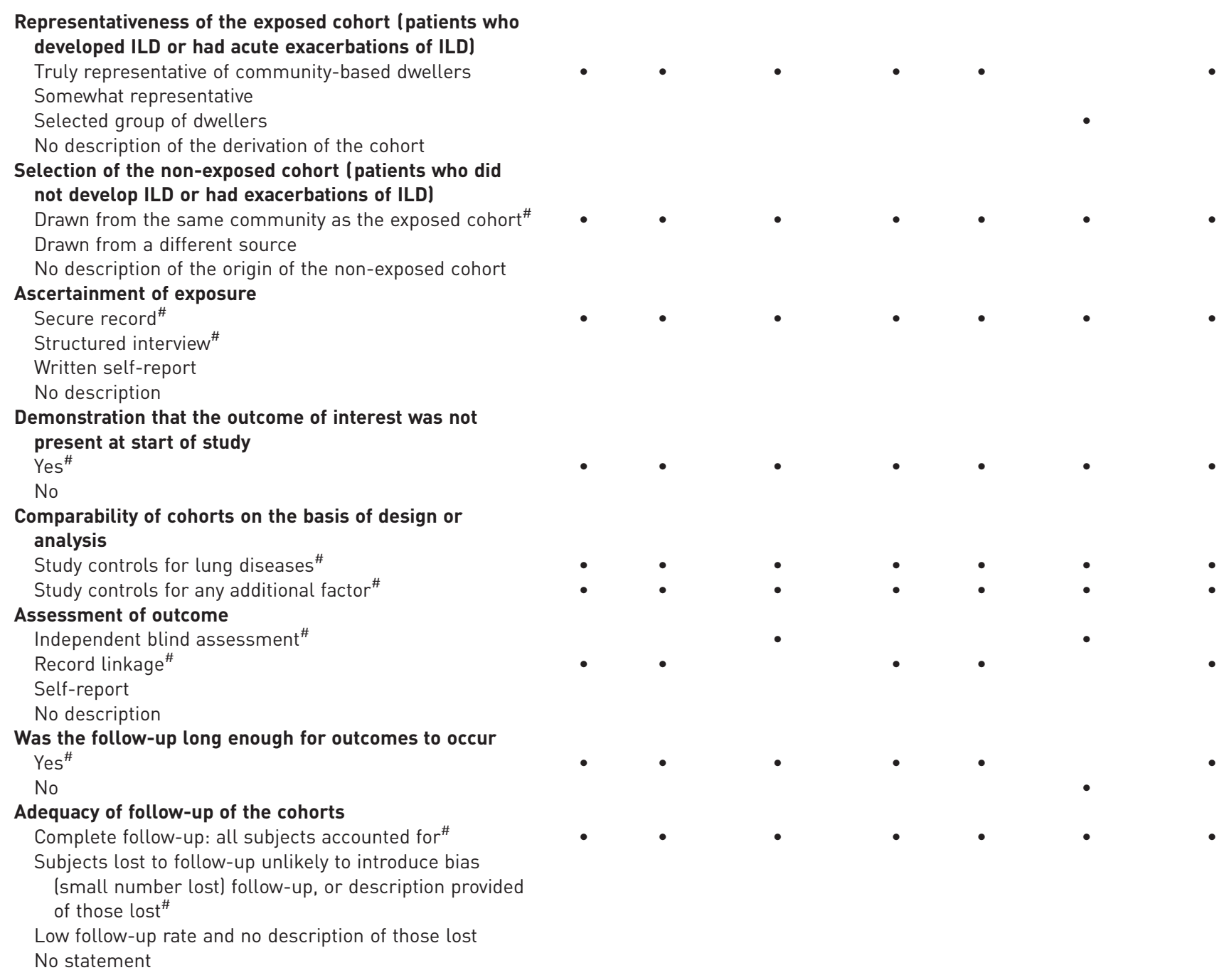

${ }^{\#}$ : study satisfies the question. 


\begin{tabular}{lccc} 
TABLE 3 Newcastle-Ottawa scale summary table & & \\
First author [ref.] & Selection & Comparability & Outcome \\
\hline SACK [24] & $* * * *$ & $* *$ & $* * *$ \\
SESÉ [14] & $* * * *$ & $* *$ & $* * *$ \\
WINTERBOTTOM [15] & $* * *$ & $* *$ & $* * *$ \\
SINGH [23] & $* * * *$ & $* *$ & $* * *$ \\
CoNTI [17] & $* * * *$ & $* *$ & $* * *$ \\
JoHANNSON [13] & $* * *$ & $* *$ & $* *$ \\
JoHANNSON [16] & $* * * *$ & $* *$ & $* * *$
\end{tabular}

A study can be awarded a maximum of four stars for selection, two for comparability and three for outcome.

to modifications in disease behaviour. Taken together, results show that pollution exposure is associated with a more compromised lung function, disease progression (defined as a decline in lung function, specifically in FVC), acute exacerbations, mortality, disease incidence and subclinical ILD. Notwithstanding the different end-points evaluated in the various studies, their message was concordant and suggested a mechanistic role for air pollution in the development and progression of IPF, that starts from subclinical interstitial lung abnormalities, early interstitial changes that indicate subclinical ILD, and thus indicates a mechanistic role of air pollutants in disease progression. The recent perspective by SACK AND RAGHU [1] shows the association of genetic factors and intrinsic and extrinsic environmental factors in the pathogenesis of IPF and fibrotic ILD.

At a time when the association between air pollution and a number of respiratory diseases (such as asthma, COPD, lung cancer, pneumonias, bronchiectasis and lung transplant) and nonrespiratory diseases [18-21, 27-39] is well established, the association with other lung diseases such as IPF and fibrotic ILD is a subject of more recent and novel interest. The existence and relevance of this association is still controversial, as shown by a recent article on the association between air pollution and lung disease that failed to mention the existence of an association between air pollution and IPF [40]. However, that there is much interest on this topic is witnessed by the fact that all the studies considered in this review were published in the last 6 years. Five of them were classified as prospective cohort studies and two were retrospective, and our assessment of bias using the NOS shows that the quality of the included studies was high.

JOHANNSON et al. [13] published the first study showing a relationship between higher levels of $\mathrm{O}_{3}$ and $\mathrm{NO}_{2}$ exposure in the previous 6 weeks and the development of acute exacerbation of IPF. SESÈ et al. [14] confirmed that short-term exposure to increased levels of $\mathrm{O}_{3}$ is a risk factor for acute exacerbation of IPF and demonstrated a statistically significant association between mortality and $\mathrm{PM}_{10}$ and $\mathrm{PM}_{2.5}$ exposure levels. Furthermore, Winterbotтом et al. [15] demonstrated a relationship between increased exposure to $\mathrm{PM}_{10}$ and an accelerated decline of FVC. In addition, JoHANNSON et al. [16] showed that higher air pollution exposure were associated with poorer lung function but not with changes in lung function. ConTI et al. [17] found a potential association between exposure to traffic-related pollution (traced with $\mathrm{NO}_{2}$ ) and the development of IPF, and SACK et al. [24] found that exposure to ambient $\mathrm{NO}_{2}$ was associated with a higher prevalence of interstitial lung abnormalities. Finally, SINGH et al. [23] showed a strong positive correlation between the prevalence of hypersensitivity pneumonitis cases and $\mathrm{PM}_{2.5}$ levels, thereby supporting the suggestion that air pollution may be a contributing factor to the pathogenesis of hypersensitivity pneumonitis.

The strengths of these included studies pertain to their longitudinal study design [14-17], broad geographical coverage, reliable albeit methodologically different measures of ambient air pollution and adequate statistical analysis. The studies included in our review were carried out in five different countries with very different pollution exposure. This condition, together with the fact that the results of the individual studies go in the same direction, strengthens the reliability of the observations.

The differences in the reported findings may be due to some degree of methodological differences between the cohorts, varying levels of air pollution exposure and outcome definition. Even though the effect size observed on the relationship between air pollution and IPF was rather small, it represents clinically relevant changes.

There are limitations pertaining to the analysed studies, such as the often small patient sample size, lack of relevant data, such as smoking history and socioeconomic level, as well as a lack of confirmation of the 
disease diagnosis. In addition, the calculation of the degree of exposure to the pollutants was perhaps somewhat inaccurate in some studies, because it is uncertain whether or not the air monitors used to measure pollutant levels were in close proximity to the patient's residences or workplaces [14, 17, 23]. Finally, the studies considered were very different in their outcomes and this made a systematic review difficult. In conclusion, this systematic review provides supporting evidence to link ambient air pollution exposure and manifestation of IPF and fibrotic ILD with poor outcomes.

\section{Suggestion for future directions}

Further studies are warranted to investigate the association of air pollution, genetic factors and fibrotic ILD, including IPF.

Follow-up with longitudinal data through ILD registries is needed to enhance further understanding with the association of air pollution and manifestation of fibrotic ILD and disease progression. In the future, it will be important to clarify the relationship between pollution and IPF progression and disease incidence though large and prospective studies. Longitudinal investigations focusing on subject-specific rather than aggregated data, preferably considering exposures at the subjects' addresses, could substantially improve the reliability of the results.

It is hoped that funding agencies will take the much needed initiative to address air pollution and preventive factors contributing to pathogenesis of fibrotic ILD worldwide. We also hope that the leadership of major respiratory societies will approach regulatory authorities/government to enhance public awareness of the entity of fibrotic ILD, especially hypersensitivity pneumonitis and air pollution in every patient confronted with ILD.

The World Health Organization and governmental agencies need to take immediate action to minimise factors contributing to air pollution and alert the public to the risk of manifesting fibrotic ILD, especially for hypersensitivity pneumonitis in susceptible persons living in urban areas known to have air pollution. Indeed, the public and healthcare communities need to be educated to prevent onset and progression of ILD contributed to by environment factors; prevention is always better than cure. It is hoped that the World Health Organization will implement certain standards to decrease air pollution globally and prevent deadly diseases such chronic hypersensitivity pneumonitis and other fibrotic lung diseases contributed to by environmental factors.

Conflict of interest: S. Harari reports grants and personal fees from Roche, outside the submitted work. G. Raghu has nothing to disclose. A. Caminati reports personal fees from Roche and Boehringer Ingelheim, outside the submitted work. M. Cruciani has nothing to disclose. M. Franchini has nothing to disclose. P. Mannucci has nothing to disclose.

\section{References}

1 Sack C, Raghu G. Idiopathic pulmonary fibrosis: unmasking cryptogenic environmental factors. Eur Respir J 2019; 53: 1801619 .

2 Raghu G, Collard HR, Egan JJ, et al. An official ATS/ERS/JRS/ALAT statement: idiopathic pulmonary fibrosis: evidence-based guidelines for diagnosis and management. Am J Respir Crit Care Med 2011; 183: 788-824.

3 Raghu G, Remy-Jardin M, Myers JL, et al. Diagnosis of idiopathic pulmonary fibrosis. An official ATS/ERS/JRS/ ALAT clinical practice guideline. Am J Respir Crit Care Med 2018; 198: e44-e68.

4 Margaritopoulos GA, Harari S, Caminati A, et al. Smoking-related idiopathic interstitial pneumonia: a review. Respirology 2016; 21: 57-64.

5 Pinheiro GA, Antao VC, Wood JM, et al. Occupational risks for idiopathic pulmonary fibrosis mortality in the United States. Int J Occup Environ Health 2008; 14: 117-123.

6 Gulati M, Redlich CA. Asbestosis and environmental causes of usual interstitial pneumonia. Curr Opin Pulm Med 2015; 21: 193-200.

7 Baumgartner KB, Samet JM, Coultas DB, et al. Occupational and environmental risk factors for idiopathic pulmonary fibrosis: a multicenter case-control study. Collaborating centers. Am J Epidemiol 2000; 152: 307-315.

8 Molyneaux PL, Maher TM. The role of infection in the pathogenesis of idiopathic pulmonary fibrosis. Eur Respir Rev 2013; 22: 376-381.

9 Taskar V, Coultas D. Exposures and idiopathic lung disease. Semin Respir Crit Care Med 2008; 29: 670-679.

10 Garantziotis S, Schwartz DA. Host-environment interactions in pulmonary fibrosis. Semin Respir Crit Care Med 2006; 27: 574-580.

11 Yang IV. Epigenomics of idiopathic pulmonary fibrosis. Epigenomics 2012; 4: 195-203.

12 Liu Y, Li H, Xiao T, et al. Epigenetics in immune-mediated pulmonary diseases. Clin Rev Allergy Immunol 2013; 45: 314-330.

13 Johannson KA, Vittinghoff E, Lee K, et al. Acute exacerbation of idiopathic pulmonary fibrosis associated with air pollution exposure. Eur Respir J 2014; 43: 1124-1131.

14 Sesé L, Nunes H, Cottin V, et al. Role of atmospheric pollution on the natural history of idiopathic pulmonary fibrosis. Thorax 2018; 73: 145-150.

15 Winterbottom CJ, Shah RJ, Patterson KC, et al. Exposure to ambient particulate matter is associated with accelerated functional decline in idiopathic pulmonary fibrosis. Chest 2018; 153: 1221-1228. 
16 Johannson KA, Vittinghoff E, Morisset J, et al. Air pollution exposure is associated with lower lung function, but not changes in lung function, in patients with idiopathic pulmonary fibrosis. Chest 2018; 154: 119-125.

17 Conti S, Harari S, Caminati A, et al. The association between air pollution and the incidence of idiopathic pulmonary fibrosis in Northern Italy. Eur Respir J 2018; 51: 1700397.

18 Turner MC, Krewski D, Pope CA 3rd, et al. Long-term ambient fine particulate matter air pollution and lung cancer in a large cohort of never-smokers. Am J Respir Crit Care Med 2011; 184: 1374-1381.

19 Faustini A, Rapp R, Forastiere F. Nitrogen dioxide and mortality: review and meta-analysis of long-term studies. Eur Respir J 2014; 44: 744-753.

20 Guarnieri M, Balmes JR. Outdoor air pollution and asthma. Lancet 2014; 383: 1581-1592.

21 Kaufman JD, Raghu G. Should we be concerned about air quality as a contributor to poor outcomes in lung transplant recipients? Eur Respir J 2017; 49: 1602369.

22 Ly H. Genetic and environmental factors influencing human diseases with telomere dysfunction. Int J Clin Exp Med 2009; 2: 114-130.

23 Singh S, Collins BF, Bairwa M, et al. Hypersensitivity pneumonitis and its correlation with ambient air pollution in urban India. Eur Respir J 2019; 53: 1801563.

24 Sack C, Vedal S, Sheppard L, et al. Air pollution and subclinical interstitial lung disease: the Multi-Ethnic Study of Atherosclerosis (MESA) air-lung study. Eur Respir J 2017; 50: 1700559.

25 Reeves BC, Deeks JJ, Higgins JPT, et al. Chapter 13: Including non-randomized studies. In: JPT Higgins, S Green, eds. Cochrane Handbook for Systematic Reviews of Interventions Version 5.1.0. Chichester, Cochrane Collaboration, 2011

26 Wells GA, Shea B, O'Connell D, et al. The Newcastle-Ottawa Scale (NOS) for assessing the quality of non-randomised studies in meta-analyses. www.ohri.ca/programs/clinical_epidemiology/oxford.asp.

27 Delfino RJ, Wu J, Tjoa T, et al. Asthma morbidity and ambient air pollution: effect modification by residential traffic-related air pollution. Epidemiology 2014; 25: 48-57.

28 Andersen ZJ, Bonnelykke K, Hvidberg M, et al. Long-term exposure to air pollution and asthma hospitalizations in older adults: a cohort study. Thorax 2012; 67: 6-11.

29 Dominici F, Peng RD, Bell ML, et al. Fine particulate air pollution and hospital admission for cardiovascular and respiratory diseases. JAMA 2006; 295: 1127-1134.

30 Pope CA, Burnett RT, Thun MJ, et al. Lung cancer, cardiopulmonary mortality and long-term exposure to fine particulate air pollution. JAMA 2002; 287: 1132-1141.

31 Smith M, Li L, Augustyn M, et al. Prevalence and correlates of airflow obstruction in 317000 never-smokers in China. Eur Respir J 2014; 44: 66-77.

32 Fang L, Gao P, Bao H, et al. Chronic obstructive pulmonary disease in China: a nationwide prevalence study. Lancet Respir Med 2018; 6: 421-430.

33 Doiron D, de Hoogh K, Probst-Hensch N, et al. Air pollution, lung function and COPD: results from the population-based UK Biobank study. Eur Respir J 2019; 54: 1802140.

34 Hoffmann B, Moebus S, Dragano N, et al. Chronic residential exposure to particulate matter air pollution and systemic inflammatory markers. Environ Health Perspect 2009; 117: 1302-1308.

35 Hoffmann B, Moebus S, Mohlenkamp S, et al. Residential exposure to traffic is associated with coronary atherosclerosis. Circulation 2007; 116: 489-496.

36 Chen H, Burnett RT, Kwong JC, et al. Risk of incident diabetes in relation to long-term exposure to fine particulate matter in Ontario, Canada. Environ Health Perspect 2013; 121: 804-810.

37 Atkinson RW, Kang S, Anderson HR, et al. Epidemiological time series studies of $\mathrm{PM}_{2.5}$ and daily mortality and hospital admissions: a systematic review and meta-analysis. Thorax 2014; 69: 660-665.

38 Zheng X-Y, Ding H, Jiang L-N, et al. Association between air pollutants and asthma emergency room visits and hospital admissions in time series studies: a systematic review and meta-analysis. PLoS One 2015; 10 : e0138146.

39 Burnett RT, Pope CA 3rd, Ezzati M, et al. An integrated risk function for estimating the global burden of disease attributable to ambient fine particulate matter exposure. Environ Health Perspect 2014; 122: 397-403.

40 Burney P, Amaral AFS. Air pollution and chronic air way disease: is the evidence always clear? Lancet 2019; 394: 2198-2200. 